\title{
Article \\ Confined Polysulfides in N-Doped 3D-CNTs Network for High Performance Lithium-Sulfur Batteries
}

\author{
Donghuang Wang ${ }^{1}$, Aijun Zhou ${ }^{1,2}$, Zhujun Yao ${ }^{3}$, Xinhui Xia ${ }^{1,4}$ and Yongqi Zhang ${ }^{1,4,5, *}$ \\ 1 Yangtze Delta Region Institute (Huzhou), University of Electronic Science and Technology of China, \\ Huzhou 313001, China; wdh@csj.uestc.edu.cn (D.W.); zhouaj0823@163.com (A.Z.); helloxxh@zju.edu.cn (X.X.) \\ 2 School of Materials and Energy, University of Electronic Science and Technology of China, \\ Chengdu 611731, China \\ 3 School of Materials Science and Engineering, Zhejiang Sci-Tech University, Hangzhou 310018, China; \\ yaozj@zstu.edu.cn \\ 4 State Key Laboratory of Silicon Materials, Key Laboratory of Advanced Materials and Applications for \\ Batteries of Zhejiang Province, School of Materials Science and Engineering, Zhejiang University, \\ Hangzhou 310027, China \\ 5 Institute of Fundamental and Frontier Sciences, University of Electronic Science and Technology of China, \\ Chengdu 611731, China \\ * Correspondence: yqzhang@uestc.edu.cn
}

Citation: Wang, D.; Zhou, A.; Yao, Z.;

Xia, X.; Zhang, Y. Confined

Polysulfides in N-Doped 3D-CNTs Network for High Performance Lithium-Sulfur Batteries. Materials 2021, 14, 6131. https://doi.org/ $10.3390 / \mathrm{ma} 14206131$

Academic Editor: Alvaro Caballero

Received: 14 September 2021

Accepted: 11 October 2021

Published: 15 October 2021

Publisher's Note: MDPI stays neutral with regard to jurisdictional claims in published maps and institutional affiliations.

Copyright: (c) 2021 by the authors. Licensee MDPI, Basel, Switzerland. This article is an open access article distributed under the terms and conditions of the Creative Commons Attribution (CC BY) license (https:// creativecommons.org/licenses/by/ $4.0 /)$.

\begin{abstract}
Improving the utilization efficiency of active materials and suppressing the dissolution of lithium polysulfides into the electrolyte are very critical for development of high-performance lithium-sulfur batteries. Herein, a novel strategy is proposed to construct a three-dimensional (3D) $\mathrm{N}$-doped carbon nanotubes (CNTs) networks to support lithium polysulfides (3D-NCNT- $\left.\mathrm{Li}_{2} \mathrm{~S}_{6}\right)$ as a binder-free cathode for high-performance lithium-sulfur batteries. The 3D N-doped CNTs networks not only provide a conductive porous 3D architecture for facilitating fast ion and electron transport but also create void spaces and porous channels for accommodating active sulfur. In addition, lithium polysulfides can be effectively confined among the networks through the chemical bond between Li and N. Owing to the synergetic effect of the physical and chemical confinement for the polysulfides dissolution, the $3 \mathrm{D}-\mathrm{NCNT}-\mathrm{Li}_{2} \mathrm{~S}_{6}$ cathodes exhibit enhanced charge capacity and cyclic stability with lower polarization and faster redox reaction kinetics. With an initial discharge capacity of $924.8 \mathrm{mAh} \mathrm{g}^{-1}$ at $1 \mathrm{C}$, the discharge capacity can still maintain $525.1 \mathrm{mAh} \mathrm{g}^{-1}$ after 200 cycles, which is better than that of its counterparts.
\end{abstract}

Keywords: lithium polysulfides; CNTs network; N-doping; lithium-sulfur battery

\section{Introduction}

There has been a strong demand of late for developing safe and cheap cathode materials with high energy density of rechargeable lithium batteries for many applications, such as portable electronic devices, electric vehicles, and the grid storage of electricity [1-8]. Among the various alternative energy storage systems, the lithium-sulfur (Li-S) batteries are considered as one of the most promising candidates for next-generation energy storage devices, owing to the extremely high theoretical specific capacity (1672 $\mathrm{mAh} \mathrm{g}^{-1}$ ) of sulfur $[9,10]$. Additionally, sulfur is a cheap, low-toxic and abundant resource, which makes Li-S batteries a particularly low-cost and attractive energy storage technology [11,12]. However, Li-S batteries still hindered by the following critical challenges [13-15]. Firstly, the element sulfur is insulating with the high resistance of about $5 \times 10^{-30} \mathrm{~S} \mathrm{~cm}^{-1}$, resulting into a low utilization of active materials and a large internal resistance and polarization of the cathode $[16,17]$. Secondly, a volume expansion of about $80 \%$ exists into electrochemical conversion of sulfur (density of $2.03 \mathrm{~g} \mathrm{~cm}^{-3}$ ) to $\mathrm{Li}_{2} \mathrm{~S}$ (density of $1.66 \mathrm{~g} \mathrm{~cm}^{-3}$ ), giving rise to structural and morphological destruction and poor columbic efficiency and rate capacity $[18,19]$. Thirdly, lithium polysulfides $\left(\operatorname{Li}_{2} \mathrm{~S}_{x}, 3 \leq x \leq 8\right)$ intermediates formed during 
the charge/discharge progress are soluble in the electrolytes, leading to a loss of active materials, self-discharge and capacity fading during extended cycling [20,21].

To address these thorny problems, various strategies are developed, including encapsulation of sulfur into conductive host materials, embedment of interlayers and optimization of the electrolytes or additives [22-25]. A relatively successful approach is to design carbon-based hosts (e.g., mesoporous carbon, hollow carbon nanofiber, graphene and carbon nanotubes) [26-30]. Typically, combination sulfur with carbon nanotubes are regarded as an effective way for construction of high-performance sulfur cathodes, which could improve both electron and ion transfer and accommodate volume changes during cycling [31-33]. However, only physical confinement is still insufficient to solve the polysulfide shuttle problem because of the open holes and weak interactions between carbon and polysulfides. Additionally, significant research effort has been made towards chemical confinement of polysulfide intermediates by heteroatom doping, especially nitrogen doping [34-37]. First-principle calculation and surface analysis further proved that polar-polar interaction and Lewis acid-base interaction with polysulfides are strong and stable [38,39]. Therefore, the nitrogen doping carbon nanotubes (CNTs) may have a significant effect on suppressing the diffusion of polysulfides and realize high-performance of lithium-sulfur batteries. Undoubtedly, it is still necessary to develop a novel and effective methodology for construction three-dimensional architecture with $\mathrm{N}$-doping as high-loading sulfur carriers and take full advantage of the interactions to suppress polysulfides diffusion for realization of high-energy and commercially viable Li-S batteries.

Herein, we develop a novel strategy to construct an integrated cathode by confining polysulfides into three-dimensional N-doped CNTs networks (3D-NCNT- $\mathrm{Li}_{2} \mathrm{~S}_{6}$ ). The $\mathrm{N}$-doped CNTs have constructed a 3D conductive networks, which not only provide conductive path for electron and ion transfer but also create large amounts of porous channels and void spaces to for a high sulfur loading. In addition, the physical and chemical confinement have a synergetic effect on suppress the polysulfides dissolution into the electrolyte. The cathodes demonstrate enhanced performance with lower polarization, better cycling stability and superior high-rate performance.

\section{Materials and Methods}

\subsection{Preparation of $3 D-N C N T-L i_{2} S_{6}$ Composite}

As reported previously, the three-dimensional CNTs network was grown on the carbon cloth (3D-CNT) by a chemical vapor deposition (CVD) method. Typically, the carbon cloth (CC) was firstly immersed in nickel nitrate ethanol solution for $5 \mathrm{~min}$ and dried under $60{ }^{\circ} \mathrm{C}$. Then the prepared carbon cloth was thermally treated at $600{ }^{\circ} \mathrm{C}$ in a mixed-gas atmosphere of $60 \mathrm{sccm} \mathrm{Ar}+5 \mathrm{sccm} \mathrm{H} \mathrm{H}_{2}$ for $30 \mathrm{~min}$. And $\mathrm{C}_{2} \mathrm{H}_{4}$ gas was introduced as a carbon source with a flow rate of $10 \mathrm{sccm}$ for another $30 \mathrm{~min}$ to obtain $3 \mathrm{D}-\mathrm{CNT}$. The $3 \mathrm{D}-\mathrm{CNT}$ was further doped nitrogen through the treatment at $550{ }^{\circ} \mathrm{C}$ with $\mathrm{NH}_{3}(30 \mathrm{sccm})$ for $1 \mathrm{~h}$ to form the 3D-NCNT.

$0.5 \mathrm{M} \mathrm{Li}_{2} \mathrm{~S}_{6}$ solution was prepared by mixing sulfur and $\mathrm{Li}_{2} \mathrm{~S}$ at a molar ratio of $5: 1$ in an appropriate amount of 1,2-dimethoxyethane and 1,3-dioxolane (DME and DOL). To fabricate 3D-NCNT- $\mathrm{Li}_{2} \mathrm{~S}_{6}$ cathode, $10 \mu \mathrm{L}$ polysulfide solution was added into $3 \mathrm{D}$-NCNT that was cut into $0.5 \times 0.5 \mathrm{~cm}^{2}$ and dried in argon atmosphere. For comparison, the 3D -CNT- $\mathrm{Li}_{2} \mathrm{~S}_{6}$ cathode was synthesized in the same way without $\mathrm{NH}_{3}$ treatment.

\subsection{Materials Characterizations}

The morphologies of these samples were investigated by scanning electron microscope (SEM, Hitachi S-4800, Tokyo, Japan) and the elemental composition and mapping were using EDS on the SEM. Raman measurements were performed on a Jobin Yvon Labor Raman HR-800 (Paris, France) using a $532 \mathrm{~nm}$ diode-pumped solid-state laser after the samples were sealed in a chamber with a glass window in glove box. Surface groups and bond of samples were characterized by an X-ray photoelectron spectroscopy (XPS, ESCAL 
220i-XL, Waltham, MA, USA), using Al K $\alpha$ X-ray radiation source in a base pressure of $10^{-7} \mathrm{~Pa}$.

\subsection{Electrochemical Measurements}

The CR2025 coin cells were assembled with the 3D-CNT- $\mathrm{Li}_{2} \mathrm{~S}_{6}$ and 3D-NCNT- $\mathrm{Li}_{2} \mathrm{~S}_{6}$ composites as the working electrode, pure lithium foil as the counter electrode and cellgard 2400 as the separator. The cells were assembled in an argon filled glove box with $\mathrm{O}_{2}$ and $\mathrm{H}_{2} \mathrm{O}$ concentration below $0.1 \mathrm{ppm}$ and $1 \mathrm{~mol} \mathrm{~L}^{-1}$ lithium bis (trifluoromethanesulfonyl) imide (LiTFSI) in 1,3-dioxolane (DOL) and 1,2-dimethoxyethane (DME) (1: 1 by volume) with $1 \mathrm{wt} . \%$ lithium nitrate $\left(\mathrm{LiNO}_{3}\right)$ as an additive was used as the electrolyte. The areal mass loading of $S$ on the electrodes is about $3.84 \mathrm{mg} \mathrm{cm}^{-2}$. All the specific capacities and current densities of cells were calculated on the basis of the mass of sulfur. The galvanostatic measurements were evaluated by the LAND battery test system in potential range from 1.7 to $2.8 \mathrm{~V}$. The cells were first discharged to $1.7 \mathrm{~V}$ and then the cycle number was counted. Cyclic voltammetry (CV) tests were carried out on a CHI660E electrochemical workstation (Shanghai, China) at a scan rate of $0.1 \mathrm{mV} \mathrm{s}^{-1}$. All the electrochemical tests were conducted at room temperature.

\section{Results and Discussion}

The fabrication of 3D-NCNT- $\mathrm{Li}_{2} \mathrm{~S}_{6}$ is schematically illustrated in Figure 1. Firstly, the three-dimensional CNTs network was grown on the carbon cloth (3D-CNT) by a CVD method. Then, the nitrogen-doping is introduced into the 3D-CNT through $\mathrm{NH}_{3}$ treatment to form the 3D-NCNT. Finally, the $\mathrm{Li}_{2} \mathrm{~S}_{6}$ solution was added into the 3D-NCNT to obtain the 3D-NCNT- $\mathrm{Li}_{2} \mathrm{~S}_{6}$ cathode.

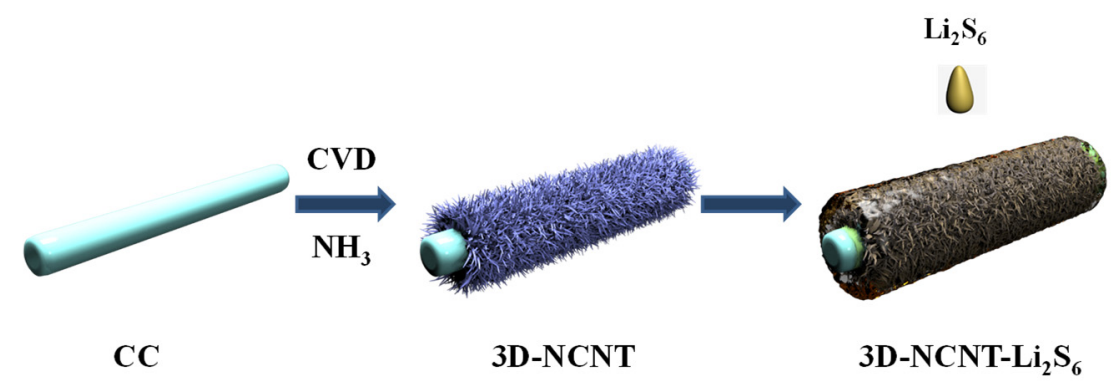

Figure 1. Illustration of synthesis $3 \mathrm{D}-\mathrm{NCNT}-\mathrm{Li}_{2} \mathrm{~S}_{6}$ composite.

\subsection{Structural Characterization}

The morphology of the samples at different stages is analyzed by SEM. As shown in Figure 2a, tens of the CNTs grow uniformly on the carbon fibers and construct a three dimensional conductive network, which ensures a fast ion/electron transportation [40,41]. The high-resolution SEM image shows that the interconnected CNTs with a diameter of $\sim 50 \mathrm{~nm}$ provide a hierarchical microporous architecture. The sufficient void space is capable of loading a large amount of active material, accommodating the volumetric expansion of sulfur and maintaining high electrolyte absorbability [42]. The 3D-NCNT still maintain their microporous architecture as the 3D-CNT, demonstrating that nitrogen doping has no damage on the structure upon $\mathrm{NH}_{3}$ treatment (Figure 2b). Figure $2 \mathrm{c}$, d present the SEM images of 3D-CNT- $\mathrm{Li}_{2} \mathrm{~S}_{6}$ and 3D-NCNT- $\mathrm{Li}_{2} \mathrm{~S}_{6}$ cathodes, the pores of the CNT and NCNT network are mostly filled with the active material. The whole structure of both cathodes is still porous, which allows efficient electrolyte penetration. It is obvious that the CNT and NCNT become thicker as they are coated by the active material and form a core-shell structure. The structure is further explored by the element mapping images of the EDS analysis (Figure 3). The elemental mapping evidently reveals the presence and homogeneous distribution of carbon, sulfur and nitrogen in the 3D-NCNT- $\mathrm{Li}_{2} \mathrm{~S}_{6}$, suggesting that the nitrogen-doping has been doped into the CNT successfully and the $\mathrm{Li}_{2} \mathrm{~S}_{6}$ uniformly cover the NCNTs [43]. 

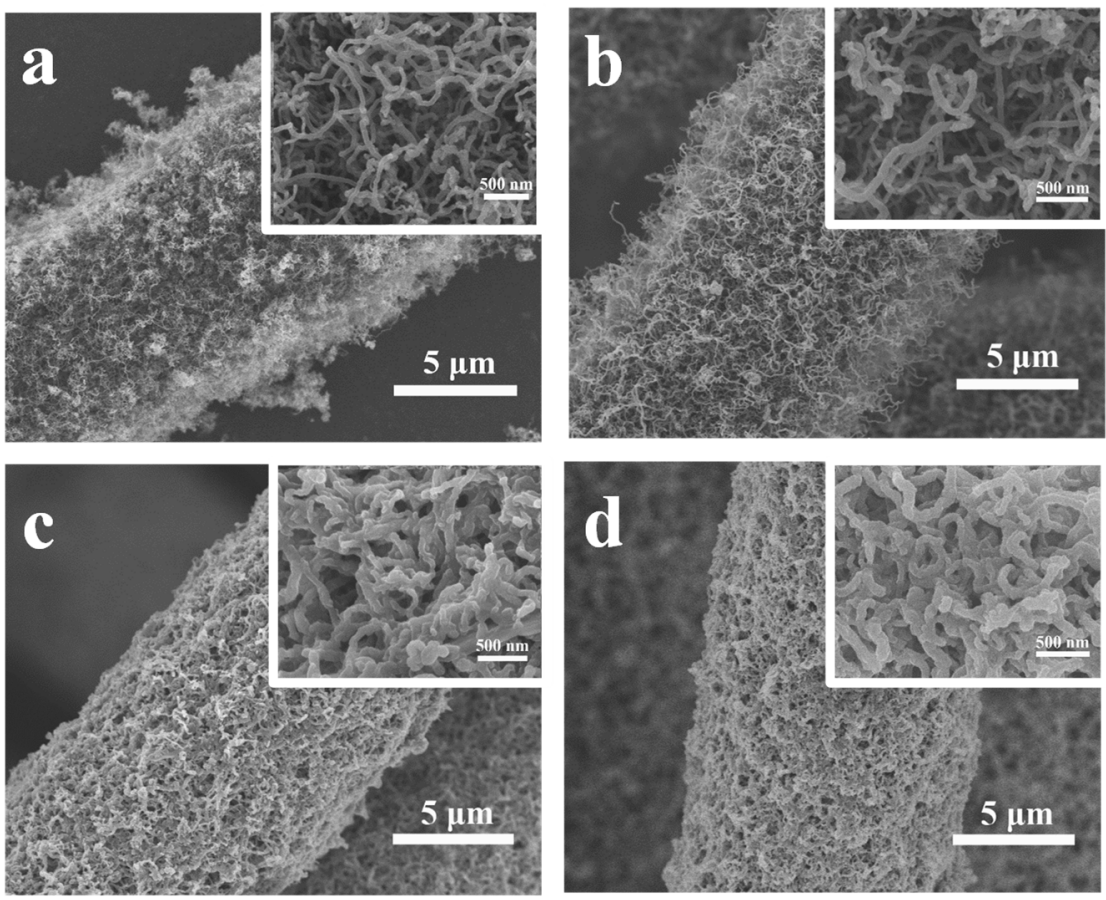

Figure 2. SEM images of (a) 3D-CNT, (b) 3D-NCNT, (c) 3D-CNT-Li $2_{2} \mathrm{~S}_{6}$ composite and (d) 3D-NCNT$\mathrm{Li}_{2} \mathrm{~S}_{6}$ composite.
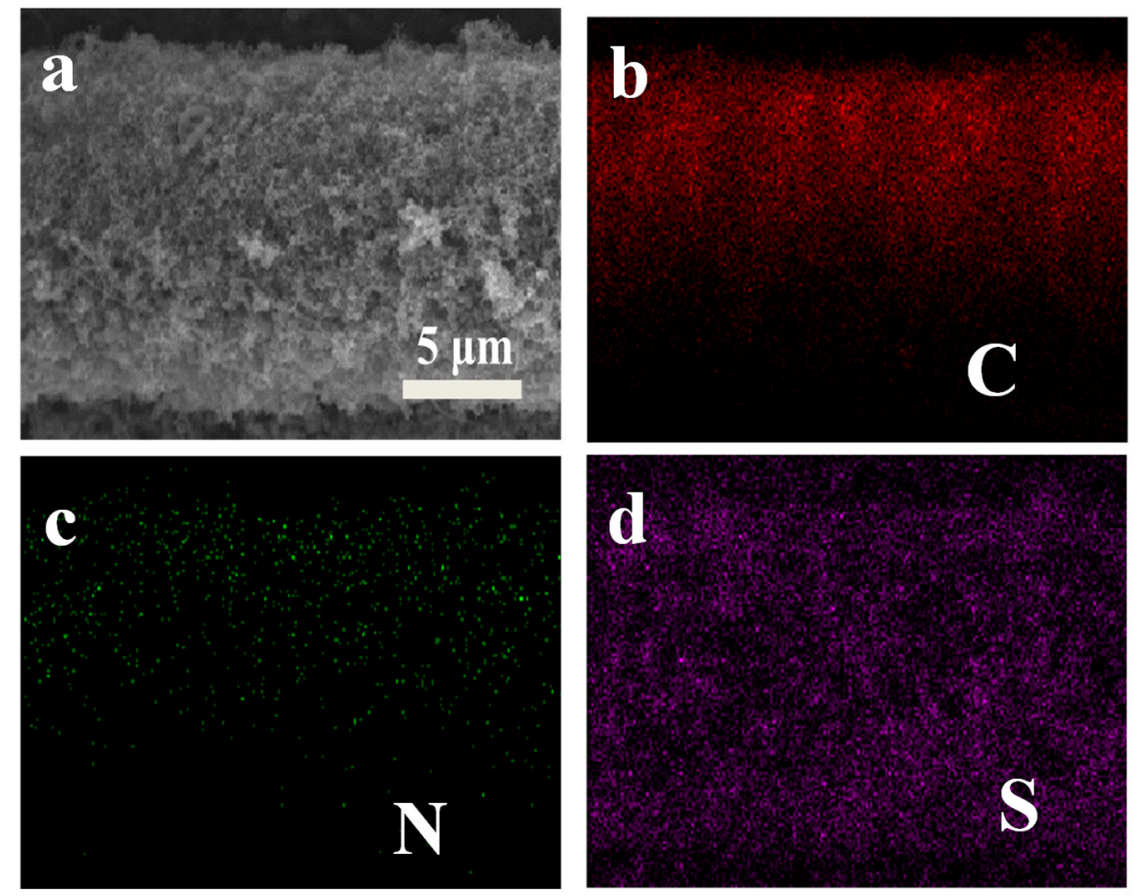

Figure 3. SEM image of (a) $3 \mathrm{D}-\mathrm{NCNT}-\mathrm{Li}_{2} \mathrm{~S}_{6}$ composite and the corresponding EDS mapping for the element distribution of (b) C, (c) N, and (d) S.

The variation of surface. chemistry of the samples is observed in Raman and X-ray photoelectron spectroscopy (XPS). As shown in Figure 4a, there are two broad peaks for 3D-CNT and 3D-NCNT at $1350 \mathrm{~cm}^{-1}$ and $1587 \mathrm{~cm}^{-1}$, which can be attributed to strong graphitic G-band and weak disorder induced D-band, respectively [44,45]. The $I_{D} / I_{G}$ ratio is an important parameter to evaluate the quality of graphic structure. The $I_{D} / I_{G}$ ratio of 3D-NCNT is higher than that of 3D-CNT indicating that more defects exist in 3D-NCNT after $\mathrm{NH}_{3}$ treatment [44]. Figure $4 \mathrm{~b}$ demonstrates the N1s spectra of 3D-NCNT, it can be 
deconvoluted into three peaks centered at 398.5, 400.2 and $402 \mathrm{eV}$, which are related to the pyridinic, pyrrolic and graphitic of $\mathrm{N}$ atoms form the nitrogen doping [46,47]. The nature of bonding between $\mathrm{N}$ atoms dopant on 3D-NCNT and polysulfide was analyzed. For $3 \mathrm{D}-\mathrm{CNT}-\mathrm{Li}_{2} \mathrm{~S}_{6}$, only a peak at $55.5 \mathrm{eV}$ corresponding to Li-S bond appears, implying no chemical bonding to 3D-CNT. Besides the Li-S bond, the 3D-NCNT-Li $\mathrm{S}_{6}$ shows an additional peak at $56.5 \mathrm{eV}$ that can be is assigned to $\mathrm{Li}-\mathrm{N}$ bond, indicating chemical bonding between $\mathrm{N}$ atoms and polysulfide $[48,49]$. Previous work has proved that $\mathrm{N}$ dopants can increase the surface basicity of 3D-CNT, strengthening the Lewis acid-base interaction between 3D-NCNT and Lewis acidic Li in polysulfide [43,44].
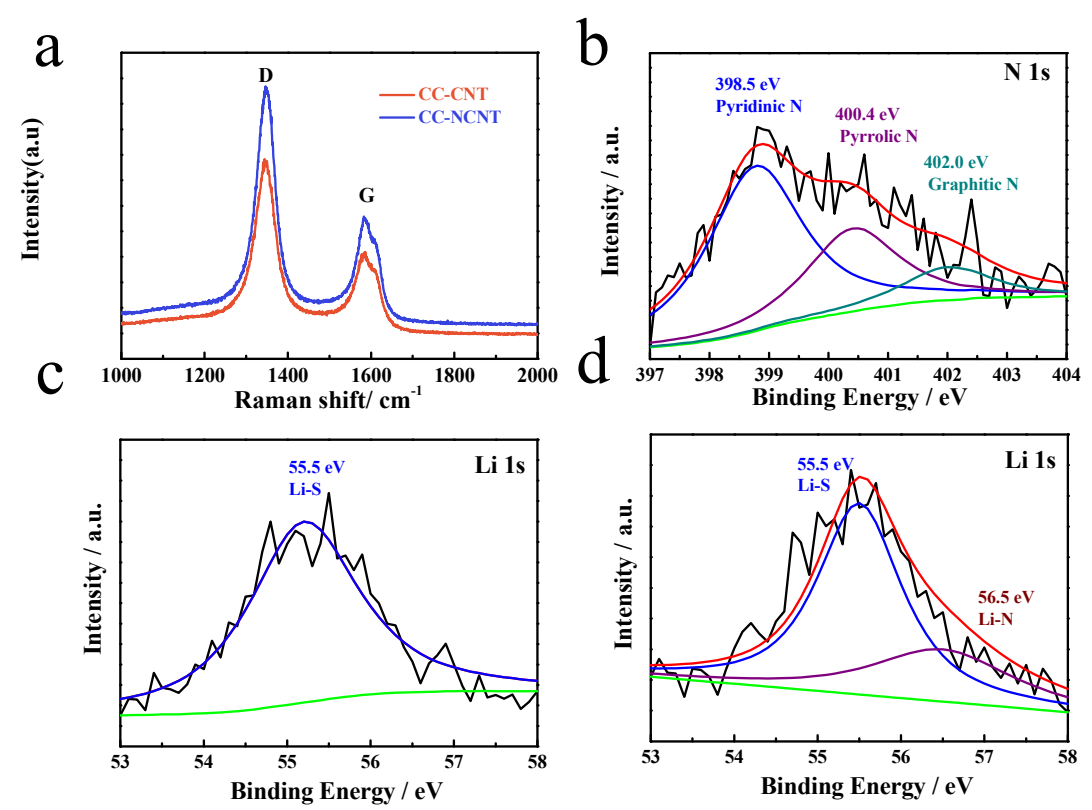

Figure 4. (a) Raman spectra of 3D-CNT and 3D-NCNT, XPS (b) N1s spectra of 3D-NCNT(c) Li1s spectra of 3D-CNT- $\mathrm{Li}_{2} \mathrm{~S}_{6}$ and (d) $3 \mathrm{D}-\mathrm{NCNT}-\mathrm{Li}_{2} \mathrm{~S}_{6}$ composite.

\subsection{Evaluation of Electrochemical Performance}

We utilized cyclic voltammetry $(\mathrm{CV})$ to investigate the electrochemical reaction kinetics. Figure 5 a displays the $\mathrm{CV}$ of $3 \mathrm{D}-\mathrm{CNT}-\mathrm{Li}_{2} \mathrm{~S}_{6}$ and $3 \mathrm{D}-\mathrm{NCNT}-\mathrm{Li}_{2} \mathrm{~S}_{6}$ in the voltage range from 1.7 to $2.8 \mathrm{~V}$ at the scan rate of $0.1 \mathrm{mV} \mathrm{s}^{-1}$, exhibiting the typical lithiation/delithiation features of sulfur cathodes [22,50]. The CV curve of 3D-CNT- $\mathrm{Li}_{2} \mathrm{~S}_{6}$ and 3D-NCNT- $\mathrm{Li}_{2} \mathrm{~S}_{6}$ both show two cathodic peaks in the reduction process, which can be attributed to the transformation of long chain $\mathrm{Li}_{2} \mathrm{~S}_{8}$ to short chain lithium polysulfides and then to the insoluble $\mathrm{Li}_{2} \mathrm{~S}_{2} / \mathrm{Li}_{2} \mathrm{~S}$, respectively. In the oxidization process, two anodic peaks are corresponding to reversible conversion from solid $\mathrm{Li}_{2} \mathrm{~S}_{2} / \mathrm{Li}_{2} \mathrm{~S}$ to short-chain lithium polysulfides and then to long-chain $\mathrm{Li}_{2} \mathrm{~S}_{8}$, respectively [10,38]. Interestingly, the 3D-NCNT- $\mathrm{Li}_{2} \mathrm{~S}_{6}$ cathode shows a distinguishable negative shift in the oxidation process and positive shift in the reduction process. Moreover, larger $\mathrm{CV}$ enclosed areas and higher peak intensities of the $3 \mathrm{D}-\mathrm{NCNT}-\mathrm{Li}_{2} \mathrm{~S}_{6}$ cathode indicates a decrease of cell polarization and improved polysulfide redox kinetics [51], which is in good agreement with the galvanostatic charge/discharge profiles at a constant current rate of $0.1 \mathrm{C}$ for the first cycle (Figure 5b). All the curves of 3D-CNT- $\mathrm{Li}_{2} \mathrm{~S}_{6}$ and 3D-NCNT- $\mathrm{Li}_{2} \mathrm{~S}_{6}$ cathodes demonstrate two typical plateaus of Li-S batteries during both the charge and discharge processes. Impressively, the 3D-NCNT- $\mathrm{Li}_{2} \mathrm{~S}_{6}$ cathode exhibits a smaller voltage gap between charge and discharge plateaus, indicating a lower polarization and the enhanced reduction efficiency of lithium polysulfides via $\mathrm{N}$ doping $[34,52]$. The promotions on the 3D-NCNT- $\mathrm{Li}_{2} \mathrm{~S}_{6}$ cathode can be further supported by electrochemical impedance spectroscopy (EIS) analysis (Figure 5f). The Nyquist plots of both cathodes consist of a single depressed semicircle in the high-medium frequency range and an inclined line in the low-frequency region, which are corresponding to the 
charge-transfer resistance $\left(R_{\mathrm{ct}}\right)$ and Warburg impedance, respectively [53]. Compared with the semicircle and intercept on the $X$-axis in the Nyquist plots of both cathodes, the 3D-NCNT-Li ${ }_{2} \mathrm{~S}_{6}$ cathode shows much lower charge-transfer resistance and Warburg impedance than that of the $3 \mathrm{D}-\mathrm{CNT}-\mathrm{Li}_{2} \mathrm{~S}_{6}$ cathode. It reveals that $\mathrm{N}$-doping reduces the inner resistance and improves the charge transfer at the electrode-electrolyte interface of the $3 \mathrm{D}-\mathrm{NCNT}-\mathrm{Li}_{2} \mathrm{~S}_{6}$ cathode due to the strongest interaction between lithium polysulfides and NCNTs $[28,34,39]$.
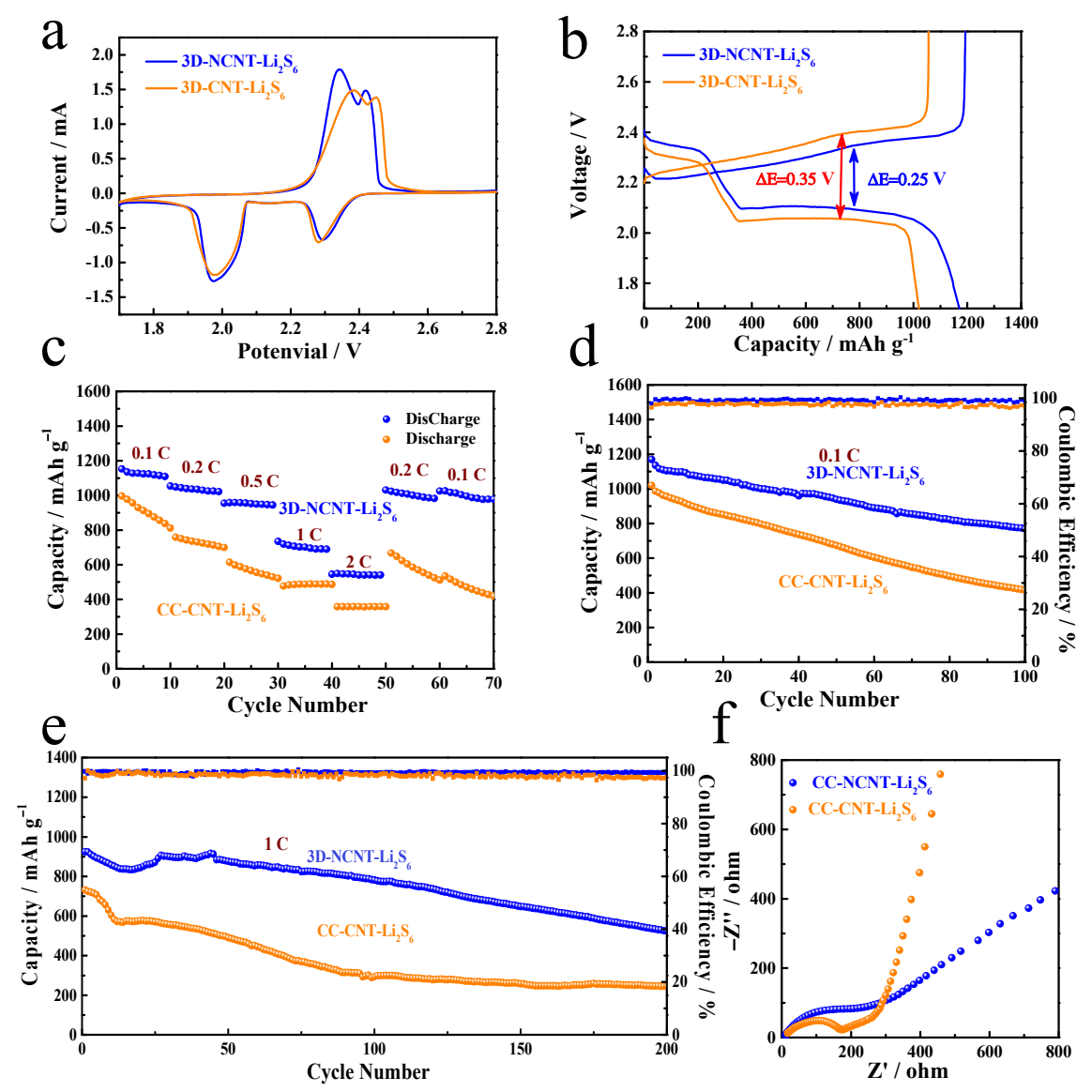

Figure 5. Comparison of electrochemical performance of 3D-CNT- $\mathrm{Li}_{2} \mathrm{~S}_{6}$ and $3 \mathrm{D}-\mathrm{NCNT}-\mathrm{Li}_{2} \mathrm{~S}_{6}$ cathodes, (a) CV curves at a scan rate of $0.1 \mathrm{mV} \mathrm{s}^{-1}$; (b) Typical voltage profiles at $0.1 \mathrm{C}$ rate for first cycle; (c) Rate performance at current rates ranging from $0.1 \mathrm{C}$ to $2 \mathrm{C}$; (d) Cycling performance at $0.1 \mathrm{C}$, (e) Cycling performance at $1 \mathrm{C}$; (f) Nyquist plots before cycling.

To evaluate the electrochemical stability of 3D-CNT- $\mathrm{Li}_{2} \mathrm{~S}_{6}$ and $3 \mathrm{D}-\mathrm{NCNT}-\mathrm{Li}_{2} \mathrm{~S}_{6}$ cathodes, the rate capability of both electrodes is tested at different currents from 0.1 to $2 \mathrm{C}$ (Figure 5c). On cycling on the current densities of $0.1 \mathrm{C}, 0.2 \mathrm{C}, 0.5 \mathrm{C}, 1 \mathrm{C}$, and $2 \mathrm{C}$, the $3 \mathrm{D}-\mathrm{NCNT}-\mathrm{Li}_{2} \mathrm{~S}_{6}$ cathode exhibits excellent rate performance with the discharge capacities of 1158.7, 1054.1, 954.7, 735.1, and $545.6 \mathrm{~mA} \mathrm{~h} \mathrm{~g}^{-1}$ (the capacity is calculated based on the mass of sulfur), respectively. Even when the current density returns back from 2 to $0.2 \mathrm{C}$ abruptly, the discharge capacity of $3 \mathrm{D}-\mathrm{NCNT}-\mathrm{Li}_{2} \mathrm{~S}_{6}$ cathode is still recovered to $1031.3 \mathrm{mAh} \mathrm{g}^{-1}$, indicating good stability and robustness. As a contrast, the 3D-CNT- $\mathrm{Li}_{2} \mathrm{~S}_{6}$ cathode reveals serious rapid capacity fading from 996.5 to $811.6 \mathrm{~mA} \mathrm{~h} \mathrm{~g}^{-1}$ at $0.1 \mathrm{C}$ for the first 10 cycles and only delivers $357.9 \mathrm{mAh} \mathrm{g}^{-1}$ at $2 \mathrm{C}$. And after the current density is switched to $0.2 \mathrm{C}$, the capacity continues to descend. 
Moreover, long cycle performance of the 3D-CNT- $\mathrm{Li}_{2} \mathrm{~S}_{6}$ and $3 \mathrm{D}-\mathrm{NCNT}-\mathrm{Li}_{2} \mathrm{~S}_{6}$ cathodes is investigated. As shown in Figure $5 \mathrm{~d}$, it can be noted that the 3D-NCNT- $\mathrm{Li}_{2} \mathrm{~S}_{6}$ cathode delivers a discharge capacity of $1170.8 \mathrm{mAh} \mathrm{g}^{-1}$ at $0.1 \mathrm{C}$, which is higher than that of the $3 \mathrm{D}-\mathrm{CNT}-\mathrm{Li}_{2} \mathrm{~S}_{6}$ cathode $\left(1020.4 \mathrm{mAh} \mathrm{g}^{-1}\right)$, indicating higher utilization of active materials. After 100 cycles, a discharge capacity of $769.7 \mathrm{mAh} \mathrm{g}^{-1}$ is obtained for the 3D-NCNT- $\mathrm{Li}_{2} \mathrm{~S}_{6}$ cathode, whereas the 3D-NCNT- $\mathrm{Li}_{2} \mathrm{~S}_{6}$ cathode only delivers a lower discharge capacity of $415.3 \mathrm{mAh} \mathrm{g}^{-1}$. Additionally, the high-rate long cycling life of the 3D-CNT- $\mathrm{Li}_{2} \mathrm{~S}_{6}$ and $3 \mathrm{D}-\mathrm{NCNT}-\mathrm{Li}_{2} \mathrm{~S}_{6}$ cathodes is evaluated (Figure 5e). Under a current density of $1 \mathrm{C}$, the 3D-NCNT- $\mathrm{Li}_{2} \mathrm{~S}_{6}$ cathode delivers a discharge capacity of $924.8 \mathrm{mAh} \mathrm{g}^{-1}$, and the discharge capacity can still maintain $525.1 \mathrm{mAh} \mathrm{g}^{-1}$ after 200 cycles. In contrast, the 3D-CNT$\mathrm{Li}_{2} \mathrm{~S}_{6}$ cathode only delivers low capacities and demonstrates fast capacity fading due to dissolution of the lithium polysulfides. Table 1 lists the performance of 3D-NCNT- $\mathrm{Li}_{2} \mathrm{~S}_{6}$ with other CNT-S and N-doping graphene-sulfur cathodes reported in the literatures. All the sulfur cathodes with $\mathrm{N}$-doping exhibit higher performance in terms of initial discharge capacity, rate capability and cycle life than that of sulfur cathodes without N-doping. The enhanced electrochemical performance can be ascribed to the $\mathrm{N}$-doping. The graphitic nitrogen state can improve the conductivity of the carbon host, and the pyridinic nitrogen state can strongly attract lithium polysulfides with large enough binding energies to effectively anchor the soluble lithium polysulfides, due to an enhanced attraction between $\mathrm{Li}$ ions in lithium polysulfides and pyridinic nitrogen state and an additional attraction between $\mathrm{S}$ anions in lithium polysulfides and $\mathrm{Li}$ ions captured by the pyridinic nitrogen state [54]. Figure 6 demonstrates the SEM images of 3D-CNT- $\mathrm{Li}_{2} \mathrm{~S}_{6}$ and 3D-NCNT- $\mathrm{Li}_{2} \mathrm{~S}_{6}$ cathodes after 200 cycles. And the morphological change provides direct evidence for suppressing the lithium polysulfide dissolution by chemical absorption. Note that the 3D-NCNT- $\mathrm{Li}_{2} \mathrm{~S}_{6}$ cathode after 200 cycles still remains the similar structure to that of the cathode before cycling, while the 3D-CNT- $\mathrm{Li}_{2} \mathrm{~S}_{6}$ cathode becomes unrecognizable, with serious aggregation. The chemisorption of lithium polysulfides on NCNT render a uniform re-deposition of sulfur or $\mathrm{Li}_{2} \mathrm{~S}$ during the charge and discharge process in conductive CNT network that gives rise to more stable and higher ionic and electronic conductivity of the 3D-NCNT- $\mathrm{Li}_{2} \mathrm{~S}_{6}$ cathode. As $\mathrm{N}$ doping in the CNTs network forms the chemical bond between $\mathrm{Li}$ and $\mathrm{N}$ that can effectively confine the lithium polysulfides among the networks, this improves the electrochemical reaction kinetics as well as enables the network catalyze the redox reactions to reduce polarization $[29,41,44]$.

Table 1. Comparison of electrochemical performances of CNT-S and N-doping graphene-sulfur electrodes.

\begin{tabular}{|c|c|c|c|}
\hline Cathode & Rate & $\begin{array}{l}\text { Initial Discharge Capacity } \\
\left(\mathrm{mAh} \mathrm{g}^{-1}\right)\end{array}$ & $\begin{array}{l}\text { Stable Discharge Capacity } \\
\left(\mathrm{mAh} \mathrm{g}^{-1}\right) \text { and Cycles }\end{array}$ \\
\hline S-CNT [55] & $0.1 \mathrm{C}$ & 1109 & 740 after 100 \\
\hline PCNT-S [56] & $0.1 \mathrm{C}$ & 895 & 625 after 100 \\
\hline CNT-S [57] & $0.1 \mathrm{C}$ & 736.8 & 408.4 after 85 \\
\hline S-MWCTs [58] & $100 \mathrm{~mA} / \mathrm{g}$ & 1330 & 854 after 30 \\
\hline CNT/S [59] & $0.1 \mathrm{C}$ & 864 & 358 after 100 \\
\hline A-3DNG/S [60] & $0.2 \mathrm{C}$ & 1101 & 860 after 200 \\
\hline N-G-S [54] & $0.3 \mathrm{~A} / \mathrm{g}$ & 1150 & 880 after 100 \\
\hline S@N-3D-rGO [61] & $0.2 \mathrm{C}^{\circ}$ & 1042 & 987 after 100 \\
\hline 3DNG-S [62] & $0.2 \mathrm{C}$ & 1050 & 990 after 100 \\
\hline 3D-NCNT-Li ${ }_{2} \mathrm{~S}_{6}$ (This work) & $0.1 \mathrm{C}$ & 1170.8 & 769.7 after 100 \\
\hline
\end{tabular}



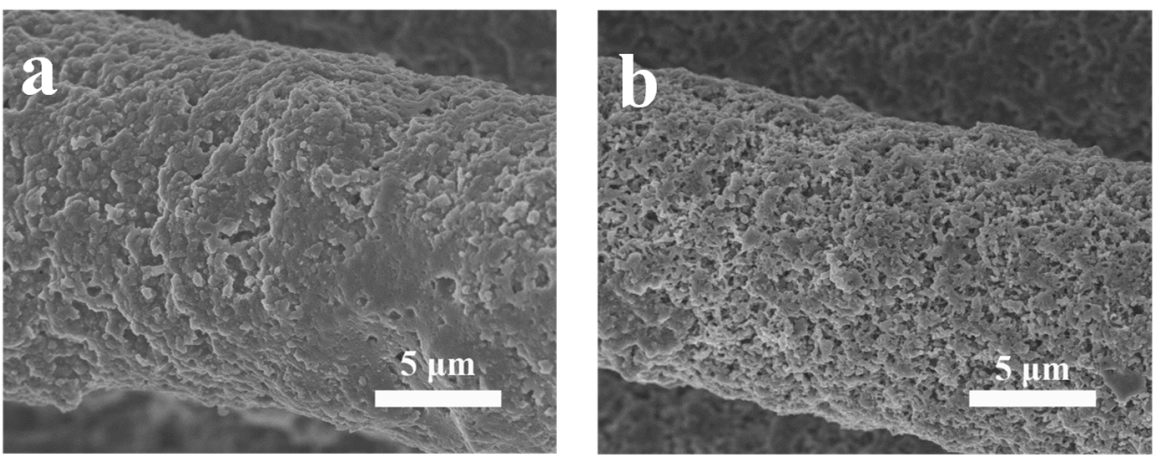

Figure 6. SEM of (a) 3D-CNT- $\mathrm{Li}_{2} \mathrm{~S}_{6}$ composite and (b) $3 \mathrm{D}-\mathrm{NCNT}-\mathrm{Li}_{2} \mathrm{~S}_{6}$ composite after cycling at $1 \mathrm{C}$ for 200 cycles.

\section{Conclusions}

In summary, we developed a novel strategy for construction of a three-dimensional $\mathrm{N}$-doped CNTs networks by using CVD technology and $\mathrm{NH}_{3}$ treatment which supports lithium polysulfides as a binder-free cathode for high-performance Li-S batteries. The three-dimensional N-doped CNTs networks not only construct a conductive porous 3D architecture for facilitating fast ion and electron transport, but they also create large amounts of void spaces and porous channels as well, for a high sulfur loading with $3.84 \mathrm{mg} \mathrm{cm}^{-2}$. In addition, lithium polysulfides can be effectively confined among the networks through the chemical bond between Li and N. Moreover, N doping in the CNTs network plays an important role in improving the electrochemical reaction kinetics as well as enabling the network to catalyze the redox reactions to reduce polarization. As a result, significantly enhanced charge capacity and cyclic stability have been achieved for the 3D-NCNT- $\mathrm{Li}_{2} \mathrm{~S}_{6}$ cathode. Therefore, our research may provide a facile and scalable way to design a binder-free lithium polysulfides based cathode for Li-S batteries in the future.

Author Contributions: D.W.: experimental design, conduct of experiment, collection of data, data analysis and manuscript writing; Z.Y.: experimental design, critical revision of this article, data analysis and interpretation; A.Z. and Y.Z.: review and editing; X.X.: critical revision of this article, final approval of article. All authors have read and agreed to the published version of the manuscript.

Funding: This research was funded by state Key Laboratory of Silicon Materials (SKL2021-12) and National Natural Science Foundation of China (Grant No. 52002052).

Institutional Review Board Statement: Not applicable.

Informed Consent Statement: Not applicable.

Data Availability Statement: The data presented in this study are available on request from the corresponding author.

Conflicts of Interest: The authors declare no conflict of interest.

\section{References}

1. Tarascon, J.M.; Armand, M. Issues and challenges facing rechargeable lithium batteries. Nature 2001, 414, 359-367. [CrossRef] [PubMed]

2. Manthiram, A.; Fu, Y.Z.; Su, Y.S. Challenges and prospects of lithium-sulfur batteries. Acc. Chem. Res. 2012, 46, 1125-1134. [CrossRef]

3. Zhong, Y.; Xia, X.H.; Deng, S.J.; Zhan, J.Y.; Fang, R.Y.; Xia, Y.; Wang, X.L.; Zhang, Q.; Tu, J.P. Popcorn inspired porous macrocellular carbon: Rapid puffing fabrication from rice and its applications in lithium-sulfur batteries. Adv. Energy Mater. 2017, 8, 1701110. [CrossRef]

4. Zhao, X.Y.; Tu, J.P.; Lu, Y.; Cai, J.B.; Zhang, Y.J.; Wang, X.L.; Gu, C.D. Graphene-coated mesoporous carbon/sulfur cathode with enhanced cycling stability. Electrochim. Acta 2013, 113, 256-262. [CrossRef]

5. Nitti, A.; Forti, G.; Bianchi, G.; Botta, C.; Tinti, F.; Gazzano, M.; Camaioni, N.; Po, R.; Pasini, D. Anthradithiophene-based organic semiconductors through regiodirected double annulations. J. Mater. Chem. C 2021, 9, 9302-9308. [CrossRef]

6. Choi, J.W.; Aurbach, D. Promise and reality of post-lithium-ion batteries with high energy densities. Nat. Rev. Mater. 2016, 1, 16013. [CrossRef] 
7. Drosos, C.; Jia, C.; Mathew, S.; Palgrave, R.G.; Moss, B.; Kafizas, A.; Vernardou, D. Aerosol-assisted chemical vapor deposition of V2O5 cathodes with high rate capabilities for magnesium-ion batteries. J. Power Sources 2018, 384, 355-359. [CrossRef]

8. Callegari, D.; Colombi, S.; Nitti, A.; Simari, C.; Nicotera, I.; Ferrara, C.; Mustarelli, P.; Pasini, D.; Quartarone, E. Autonomous Self-Healing Strategy for Stable Sodium-Ion Battery: A Case Study of Black Phosphorus Anodes. ACS Appl. Mater. Interfaces 2021, 13, 13170-13182. [CrossRef] [PubMed]

9. Niu, X.Q.; Wang, X.L.; Wang, D.H.; Li, Y.; Zhang, Y.J.; Yang, T.; Yu, T.; Tu, J.P. Metal hydroxide-a new stabilizer for the construction of sulfur/carbon composites as high-performance cathode materials for lithium-sulfur batteries. J. Mater. Chem. A 2015, 3, 17106-17112. [CrossRef]

10. Yang, Y.; Zheng, G.Y.; Cui, Y. Nanostructured sulfur cathodes. Chem. Soc. Rev. 2013, 42, 3018-3032. [CrossRef]

11. Manthiram, A.; Fu, Y.; Chung, S.H.; Zu, C.; Su, Y.S. Rechargeable lithium-sulfur batteries. Chem. Rev. 2014, 114, 11751-11787. [CrossRef]

12. Li, S.H.; Wang, X.H.; Xia, X.H.; Wang, Y.D.; Wang, X.L.; Tu, J.P. Sulfur cathode integrated with multileveled carbon nanoflakenanosphere networks for high-performance lithium-sulfur batteries. Electrochim. Acta 2017, 227, 217-224. [CrossRef]

13. Xu, G.Y.; Ding, B.; Pan, J.; Nie, P.; Shen, L.F.; Zhang, X.G. High performance lithium-sulfur batteries: Advances and challenges. J. Mater. Chem. A 2014, 2, 12662-12676. [CrossRef]

14. Li, Z.; Huang, Y.M.; Yuan, L.X.; Hao, Z.X.; Huang, Y.H. Status and prospects in sulfur-carbon composites as cathode materials for rechargeable lithium-sulfur batteries. Carbon 2015, 92, 41-63. [CrossRef]

15. Shan, X.; Zhong, Y.; Zhang, L.; Zhang, Y.; Xia, X.; Wang, X.; Tu, J. A Brief Review on Solid Electrolyte Interphase Composition Characterization Technology for Lithium Metal Batteries: Challenges and Perspectives. J. Phys. Chem. C 2021, 125, 19060-19080. [CrossRef]

16. Niu, X.Q.; Wang, X.L.; Xie, D.; Wang, D.H.; Zhang, Y.D.; Li, Y.; Yu, T.; Tu, J.P. Nickel hydroxide-modified sulfur/carbon composite as a high-performance cathode material for lithium sulfur battery. ACS Appl. Mater. Interfaces 2015, 7, 16715-16722. [CrossRef] [PubMed]

17. Pang, Q.; Nazar, L.F. Long-life and high-areal-capacity Li-S batteries enabled by a light-weight polar host with intrinsic polysulfide adsorption. ACS Nano 2016, 10, 4111-4118. [CrossRef]

18. Zhang, G.; Zhang, Z.W.; Peng, H.J.; Huang, J.Q.; Zhang, Q. A toolbox for lithium-sulfur battery research: Methods and protocols. Small Methods 2017, 1, 1700134. [CrossRef]

19. Zhang, C.; Wu, H.B.; Yuan, C.; Guo, Z.; Lou, X.W. Confining sulfur in double-shelled hollow carbon spheres for lithium-sulfur batteries. Angew. Chem. 2012, 124, 9730-9733. [CrossRef]

20. Cao, R.G.; Xu, W.; Lv, D.P.; Xiao, J.; Zhang, J.G. Anodes for rechargeable lithium-sulfur batteries. Adv. Energy Mater. 2015, 5, 1402273. [CrossRef]

21. Wild, M.; O’Neill, L.; Zhang, T.; Purkayastha, R.; Minton, G.; Marinescu, M.; Offer, G.J. Lithium sulfur batteries, a mechanistic review. Energy Environ. Sci. 2015, 8, 3477-3494. [CrossRef]

22. Pope, M.A.; Aksay, I.A. Structural design of cathodes for Li-S batteries. Adv. Energy Mater. 2015, 5, 1500124. [CrossRef]

23. Zhang, S.S. A new finding on the role of $\mathrm{LiNO}_{3}$ in lithium-sulfur battery. J. Power Sources 2016, 322, 99-105. [CrossRef]

24. Zhang, S.S. Role of $\mathrm{LiNO}_{3}$ in rechargeable lithium/sulfur battery. Electrochim. Acta 2012, 70, 344-348. [CrossRef]

25. Zhao, Y.; Zhang, X.; He, Y.; Liu, N.; Tan, T.; Liang, C. Biomass derived nitrogen-doped highly porous carbon material with a hierarchical porous structure for high-performance lithium/sulfur batteries. Materials 2017, 10, 1158. [CrossRef]

26. Kim, J.H.; Kim, T.; Jeong, Y.C.; Lee, K.; Park, K.T.; Yang, S.J.; Park, C.R. Stabilization of insoluble discharge products by facile aniline modification for high performance Li-S batteries. Adv. Energy Mater. 2015, 5, 150028. [CrossRef]

27. Lee, J.S.; Kim, W.; Jang, J.; Manthiram, A. Sulfur-embedded activated multichannel carbon nanofiber composites for long-life, high-rate lithium-sulfur batteries. Adv. Energy Mater. 2017, 7, 1601943. [CrossRef]

28. Wang, X.W.; Zhang, Z.; Qu, Y.H.; Lai, Y.Q.; Li, J. Nitrogen-doped graphene/sulfur composite as cathode material for high capacity lithium-sulfur batteries. J. Power Sources 2014, 256, 361-368. [CrossRef]

29. $\mathrm{Wu}, \mathrm{M}$.; Cui, Y.; Fu, Y. $\mathrm{Li}_{2} \mathrm{~S}$ nanocrystals confined in free-standing carbon paper for high performance lithium-sulfur batteries. ACS Appl. Mater. Interfaces 2015, 7, 21479-21486. [CrossRef]

30. Cen, T.; Zhang, Y.; Tian, Y.; Zhang, X. Synthesis and electrochemical performance of graphene@halloysite nanotubes/sulfur composites cathode materials for lithium-sulfur batteries. Materials 2020, 13, 5158. [CrossRef]

31. Jin, F.; Xiao, S.; Lu, L.; Wang, Y. Efficient activation of high-loading sulfur by small CNTs confinedinside a large CNT for high-capacity and high-rate lithium-sulfur batteries. Nano Lett. 2016, 16, 440-447. [CrossRef]

32. Hu, G.; Sun, Z.; Shi, C.; Fang, R.; Chen, J.; Hou, P.; Liu, C.; Cheng, H.M.; Li, F. A sulfur-rich copolymer@CNT hybrid cathode with dual-confinement of polysulfides for high-performance lithium-sulfur batteries. Adv. Mater. 2017, 29, 1603835. [CrossRef]

33. Hong, X.H.; Jin, J.; Wu, T.; Lu, Y.; Zhang, S.P.; Chen, C.H.; Wen, Z.Y. rGO-CNT aero gel covalently bonded with a nitrogen-rich polymer as a polysulfide adsorptive cathode for high sulfur loading lithium sulfur battery. J. Mater. Chem. A 2017, 5, 14775-14782. [CrossRef]

34. Niu, S.; Lv, W.; Zhou, G.; He, Y.; Li, B.; Yang, Q.H.; Kang, F. N and S co-doped porous carbon spheres prepared using L-cysteine as a dual functional agent for high-performance lithium-sulfur batteries. Chem. Commun. 2015, 51, 17720-17723. [CrossRef]

35. Lin, Z.; Waller, G.H.; Liu, Y.; Liu, M.; Wong, C.P. 3D Nitrogen-doped graphene prepared by pyrolysis of graphene oxide with polypyrrole for electrocatalysis of oxygen reduction reaction. Nano Energy 2013, 2, 241-248. [CrossRef] 
36. Xu, J.; Wang, M.; Wickramaratne, N.P.; Jaroniec, M.; Dou, S.; Dai, L. High-performance sodium ion batteries based on a 3D anode from nitrogen-doped graphene foams. Adv. Mater. 2015, 27, 2042-2048. [CrossRef] [PubMed]

37. Chen, F.; Ma, L.; Ren, J.; Zhang, M.; Luo, X.; Li, B.; Song, Z.; Zhou, X. Wheat straw-derived N-, O-, and S-Tri-doped porous carbon with ultrahigh specific surface area for lithium-sulfur batteries. Materials 2018, 11, 989. [CrossRef] [PubMed]

38. Zhang, J.; Huang, H.; Bae, J.; Chung, S.H.; Zhang, W.K.; Manthiram, A.; Yu, G.H. Nanostructured host materials for trapping sulfur in rechargeable Li-S batteries: Structure design and interfacial chemistry. Small Methods 2018, 2, 1700279. [CrossRef]

39. Li, C.; Xi, Z.; Guo, D.; Chen, X.; Yin, L. Chemical immobilization effect on lithium polysulfides for lithium-sulfur batteries. Small 2018, 14, 1701986. [CrossRef] [PubMed]

40. Wu, F.X.; Magasinski, A.; Yushin, G. Nanoporous $\mathrm{Li}_{2} \mathrm{~S}$ and MWCNT-linked $\mathrm{Li}_{2} \mathrm{~S}$ powder cathodes for lithium-sulfur and lithium-ion battery chemistries. J. Mater. Chem. A 2014, 2, 6064-6070. [CrossRef]

41. He, J.R.; Chen, Y.F.; Lv, W.G.; Wen, K.C.; Xu, C.; Zhang, W.L.; Qin, W.; He, W.D. Three-dimensional CNT/graphene-Li 2 S aerogel as freestanding cathode for high-performance Li-S batteries. ACS Energy Lett. 2016, 1, 820-826. [CrossRef]

42. Ye, X.M.; Ma, J.; Hu, Y.S.; Wei, H.Y.; Ye, F.F. MWCNTs porous microspheres with efficient 3D conductive network for high performance lithium-sulfur batteries. J. Mater. Chem. A 2015, 4, 775-780. [CrossRef]

43. Wu, H.L.; Xia, L.; Ren, J.; Zheng, Q.J.; Xu, C.G.; Lin, D.M. A high-efficiency N/P co-doped graphene/CNT@porous carbon hybrid matrix as a cathode host for high performance lithium-sulfur batteries. J. Mater. Chem. A 2017, 5, 20458-20472. [CrossRef]

44. Wang, X.; Gao, T.; Han, F.; Ma, Z.; Zhang, Z.; Li, J.; Wang, C. Stabilizing high sulfur loading Li-S batteries by chemisorption of polysulfide on three-dimensional current collector. Nano Energy 2016, 30, 700-708. [CrossRef]

45. Tang, H.; Zhang, J.; Zhang, Y.J.; Xiong, Q.Q.; Tong, Y.Y.; Li, Y.; Wang, X.L.; Gu, C.D.; Tu, J.P. Porous reduced graphene oxide sheet wrapped silicon composite fabricated by steam etching for lithium-ion battery application. J. Power Sources 2015, 286, 431-437. [CrossRef]

46. Su, D.W.; Cortie, M.; Wang, G.X. Fabrication of N-doped graphene-carbon nanotube hybrids from prussian blue for lithium-sulfur batteries. Adv. Energy Mater. 2017, 7, 1602014. [CrossRef]

47. Ji, J.; Liu, J.; Lai, L.; Zhao, X.; Zhen, Y.; Lin, J.; Zhu, Y.; Ji, H.; Zhang, L.L.; Ruoff, R.S. In situ activation of nitrogen-doped graphene anchored on graphite foam for a high-capacity anode. ACS Nano 2015, 9, 8609-8616. [CrossRef] [PubMed]

48. Hu, C.; Kirk, C.; Cai, Q.; Cuadrado Collados, C.; Silvestre Albero, J.; Rodríguez Reinoso, F.; Biggs, M.J. A high-volumetric-capacity cathode based on interconnected close-packed N-doped porous carbon nanospheres for long-life lithium-sulfur batteries. Adv. Energy Mater. 2017, 7, 1701082. [CrossRef]

49. Zhang, J.; Shi, Y.; Ding, Y.; Peng, L.L.; Zhang, W.K.; Yu, G.H. A conductive molecular framework derived Li 2 S/N,P-codoped carbon cathode for advanced lithium-sulfur batteries. Adv. Energy Mater. 2017, 7, 1602876. [CrossRef]

50. Seh, Z.W.; Sun, Y.; Zhang, Q.; Cui, Y. Designing high-energy lithium-sulfur batteries. Chem. Soc. Rev. 2016, 45, 5605-5634. [CrossRef] [PubMed]

51. Li, L.; Chen, L.; Mukherjee, S.; Gao, J.; Sun, H.; Liu, Z.; Ma, X.; Gupta, T.; Singh, C.V.; Ren, W.; et al. Phosphorene as a polysulfide immobilizer and catalyst in high-performance lithium-sulfur batteries. Adv. Mater. 2016, 29, 1602734. [CrossRef] [PubMed]

52. Zhong, M.E.; Guan, J.D.; Feng, Q.J.; Wu, X.W.; Xiao, Z.B.; Zhang, W.; Tong, S.; Zhou, N.; Gong, D.X. Accelerated polysulfide redox kinetics revealed by ternary sandwich-type S@Co/N-doped carbon nanosheet for high-performance lithium-sulfur batteries. Carbon 2018, 128, 86-96. [CrossRef]

53. Wang, D.H.; Xie, D.; Xia, X.H.; Zhang, X.Q.; Tang, W.J.; Zhong, Y.; Wu, J.B.; Wang, X.L.; Tu, J.P. A 3D conductive network with high loading $\mathrm{Li}_{2} \mathrm{~S} @ \mathrm{C}$ for high performance lithium-sulfur batteries. J. Mater. Chem. A 2017, 5, 19358-19363. [CrossRef]

54. Li, L.; Zhou, G.; Yin, L.; Koratkar, N.; Li, F.; Cheng, H.-M. Stabilizing sulfur cathodes using nitrogen-doped graphene as a chemical immobilizer for Li S batteries. Carbon 2016, 108, 120-126. [CrossRef]

55. Jin, K.; Zhou, X.; Zhang, L.; Xin, X.; Wang, G.; Liu, Z. Sulfur/Carbon Nanotube Composite Film as a Flexible Cathode for Lithium-Sulfur Batteries. J. Phys. Chem. C 2013, 117, 21112-21119. [CrossRef]

56. Xiao, Z.; Yang, Z.; Nie, H.; Lu, Y.; Yang, K.; Huang, S. Porous carbon nanotubes etched by water steam for high-rate large-capacity lithium-sulfur batteries. J. Mater. Chem. A 2014, 2, 8683-8689. [CrossRef]

57. Cheng, X.-B.; Huang, J.-Q.; Zhang, Q.; Peng, H.-J.; Zhao, M.-Q.; Wei, F. Aligned carbon nanotube/sulfur composite cathodes with high sulfur content for lithium-sulfur batteries. Nano Energy 2014, 4, 65-72. [CrossRef]

58. Ahn, W.; Kim, K.-B.; Jung, K.-N.; Shin, K.-H.; Jin, C.-S. Synthesis and electrochemical properties of a sulfur-multi walled carbon nanotubes composite as a cathode material for lithium sulfur batteries. J. Power Sources 2012, 202, 394-399. [CrossRef]

59. Zhu, L.; Zhu, W.; Cheng, X.-B.; Huang, J.-Q.; Peng, H.-J.; Yang, S.-H.; Zhang, Q. Cathode materials based on carbon nanotubes for high-energy-density lithium-sulfur batteries. Carbon 2014, 75, 161-168. [CrossRef]

60. Benítez, A.; Caballero, A.; Morales, J.; Hassoun, J.; Rodríguez-Castellón, E.; Canales-Vázquez, J. Physical activation of graphene: An effective, simple and clean procedure for obtaining microporous graphene for high-performance Li/S batteries. Nano Res. 2019, 12, 759-766. [CrossRef]

61. Zegeye, T.A.; Tsai, M.-C.; Cheng, J.-H.; Lin, M.-H.; Chen, H.-M.; Rick, J.; Su, W.-N.; Kuo, C.-F.J.; Hwang, B.-J. Controllable embedding of sulfur in high surface area nitrogen doped three dimensional reduced graphene oxide by solution drop impregnation method for high performance lithium-sulfur batteries. J. Power Sources 2017, 353, 298-311. [CrossRef]

62. Benítez, A.; Di Lecce, D.; Caballero, Á.; Morales, J.; Rodríguez-Castellón, E.; Hassoun, J. Lithium sulfur battery exploiting material design and electrolyte chemistry: 3D graphene framework and diglyme solution. J. Power Sources 2018, 397, 102-112. [CrossRef] 